\title{
A ALTA DO PACIENTE CIRÚRGICO NO CONTEXTO DO SISTEMA DE SAÚDE*
}

\author{
Olga Maimoni Aguillar** \\ Emilia Luigia Saporiti Angerami***
}

AGUILLAR, O,M.: ANGERAMI, E.L.S. A alta do paciente cirúrgico no contexto do sistema de saúde. Rev. Esc. Enf. USP., v. 26, n. 3, p. - , dez., 1992.

Partindo-se da premissa de que o paciente cirningico e a sua familia, têm assumido a responsabilidade do seu cuidado após a alta hospitalar é que propusemos o presente trabalho. Tivemos como objetivos, estudar os problemas apresentados pelos pacientes cirúrgicos relativos a alta hospitalar e conhecer o processo de atendimento a estas pessoas no contexto do sistema de sauide. Participaram do estudo pacientes que foram submetidos d cirurgia eletiva de médio porte, no Hospital das Clinicas da Faculdade de Medicina de Ribeirão Preto-USP, no primeiro semestre de 1989. Atraves de visitas domiciliárias, foram entrevistados 50 pacientes sendo que destes, 42 do sexo feminino e 08 de sexo masculino, das diversas especialidades ciruirgicas.

$A$ analise dos dados foi realizada de forma descritiva e tendo como base o referencial teórico de Lalonde, que vê a saúde como resultante de um processo dinamico de integração do individuo com o seu meio ambiente. Dessa forma, chegou-se a algumas conclusóes a respeito do grupo estudado.

Concluiu-se o estudo apresentando sugestōes, abordando aspectos de administração de saúde e de assistência de enfermagem.

UNITERMOS: Paciente Cinúrgico. Alta hospitalar. Avaliação pós-operatória de pacientes no domicilio.

\section{Introduçáo}

Como estabelecido nas várias décadas pela Organização Mundial de Saúde, a saúde é um direito humano básico e um bem valorizado socialmente. Neste sentido, a saúde tem sido discutida amplamente durante os últimos anos, em numerosos países, na tentativa de se encontrar alternativas que apontem para a melhoria dos níveis de saúde da população.

$\mathrm{Na}$ Conferência Internacional sobre Cuidados Primários de Saúde, ocorrida em Alma-Ata - URSS(17), em 1978, ficou evidenciada a necessidade de reo-

- Resumo de Tese de Doutorado apresentada à Escola de Enfermagem de Ribeirão Preto dä Universidade de São Paulo, 1990.

** Professr Doutor - Escola de Enfermagem de Ribeirão Preto - Universidade de São Paulo.

*** Professor Titular - Escola de Enfermagem de Ribeirão Preto - Universidade de Sāo Paulo. 
rientação das políticas governamentais, não só do setor saúde, mas dos demais setores que se encontram relacionados na determinação da qualidade de vida das populaçőes(16). Desta forma, dentre outros aspectos abordados, passa a preocupação universal com a racionalização dos recursos em saúde, numa tentativa de controle de custos sem detrimento da assistência devida à população.

No Brasil, a lei número 6229 , dispondo sobre a organização do Sistema Nacional de Saúde, data de 1975, entretanto, os serviços nesta área não atendem ainda às expectativas da população. Atualmente o setor enfrenta uma série de problemas de ordem político-administrativa, que tem colaborado para o distanciamento das metas propostas em Alma-Ata(14,21). Observa-se no atual sistema, inapropriada distribuição geográfica dos serviços de atendimento, que por sua vez estão inadequadamente aparelhados, observando-se a tendéncia à utilização de tecnologia sofisticada. A alta tecnologia tem motivado gastos elevados e muitas vezes supérfluos, principalmente no atendimento hospitalar, que não tem sido acompanhada de melhoria significativa nos níveis de saúde da população(14,21).

As ações básicas de saúde vêm se mantendo em nível secundário de prioridade e se desenvolvem de forma desvinculada do atendimento hospitalar(1). Têm se limitado a campanhas eventuais e a programas que não atendem às reais necessidades da população pois, não têm como base os dados epidemiológicos locais e não contam com a participação da comunidade no seu planejamento.

O contingente de recursos humanos também constitui um problema básico em saúde que não tem sido devidamente priorizado(7). Na área especifica de enfermagem, força de trabalho essencial do setor, observa-se a discrepância representada pela escassez de pessoal de nível médio e superior e o grande número de pessoas não habilitadas, de nível elementar, sendo treinadas pelos próprios serviços.

Estes fatores têm colaborado para a ineficiência e ineficácia na resolução dos problemas de saúde da população.

A atual política de saúde, vem propondo a racionalização de recursos e a melhoria da assistência a ser prestada. Para alcançar seus objetivos, uma das estratégias propostas é o atendimento por níveis de atenção, ou seja, por níveis de complexidade crescente. Assim, Serviço de Atenção Primária é onde se dá o primeiro contato do cliente com o sistema formal de saúde. Serve como triagem e referência para os demais serviços. Serviço de Atenção Secundária, fornece atendimento nas diversas especialidades clínicas e cirúrgicas. A clientela referida a estes hospitais pelos níveis primários de atenção, para eles deve retornar. E finalmente, Serviço de Atenção Terciária é a assistência mais complexa com alto grau de especialização em recursos humanos e materiais(12).

Atuando no setor saúde e convivendo com suas muitas limitaçōes, passamos a refletir a respeito da reorganização pela qual está passando o sistema e consideramos oportuno estudarmos a forma pela qual vem se dando a assistência à saúde em nossa cidade.

Trabalhando na área de enfermagem cirúrgica, setor secundário e terciário da assistência, a nossa preocupação se voltou mais especificamente para o atendimento ao paciente cirúrgico e para a questão da alta hospitalar destes pacientes. 
Nós, profissionais da área da saúde, freqüentemente vemos a alta hospitalar como o final triunfante de uma longa série de sofisticados cuidados médicos e de enfermagem. Na realidade, a alta é uma ponte entre os cuidados hospitalares e os domicialiares(19).

A alta freqüentemente é considerada sinônimo de sucesso e de missão cumprida, entretanto, sabe-se que é grande o número de pessoas que retornam ao hospital com problemas que poderiam ter sido prevenidos ou controlados(4).

Enfoques recentes, têm considerado a alta hospitalar como um processo de transferencia da responsabilidade do cuidado ao paciente, familia ou outros profissionais de saúde(6).

Neste sentido, consideramos potencialmente crítico o processo de alta hospitalar do paciente cirúrgico, tendo em vista as suas especificidades e o fato de que dentro do processo cirúrgico, o pós-operatorio é o período de restabelecimento do indivíduo frente à agressão sofrida pela cirurgia.

Neste período, uma série de fatores estarão influenciando no sentido de favorecer ou năo a sua recuperação e podendo inclusive colocar em risco a efetividade do tratamento realizado.

A partir destas considerações, algumas questões vêm nos inquietando enquanto enfermeira e pesquisadora: Quem tem assumido a responsabilidade da assistência ao paciente que sai de alta hospitalar e ainda necessita de cuidados? Que problemas têm sido vivenciados pelo paciente e famíia ao realizarem estes cuidados? Que sistema de apoio à saúde dispõem para auxiliar em suas dificuldades? Como ocorre a recuperação do paciente no seu domićlio? Quem tem colaborado para facilitar essa recuperação? $(8,9,13,19)$.

A literatura internacional, tem mostrado que em países onde a assistência à saúde é melhor estruturada, é grande a ênfase que é dada à alta hospitalar, que é programada desde a internação do paciente, por grupos multiprofissionais, a fim de que seja assegurada a qualidade da assistência no pós-operatório.

No Brasil, são praticamente inexistentes programas sistematizados para a alta, tanto a nível hospitalar como extra-hospitalar.

\section{Objetivos do Trabalho}

O presente trabalho tem como objetivos:

1. Detectar de que forma está se dando o acesso de pacientes cirúrgicos ao serviço de atenção terciária, tendo em vista as mudanças que vêm ocorrendo no Sistema Nacional de Saúde e a proposta de atendimento por níveis de atençăo.

2. Conhecer as características do grupo de pacientes que procuram este serviço.

3. Conhecer os problemas enfrentados pelo paciente cirúrgico após a alta hospitalar e as soluções que tem sido dadas a eles.

4. Saber quem efetivamente tem assumido a responsabilidade do cuidado após a alta e qual o sistema de apoio para o seu seguimento.

5. Obter informações a respeito do preparo do paciente e da família para a alta.

6. Conhecer a percepção do paciente cirúrgico frente ao atendimento recebido. 
Tendo em vista estes objetivos, utilizamos para o nosso estudo, o referencial teórico de Lalonde(3,5,18), que vê a saúde como resultante de um processo dinâmico de integração do indivíduo com o seu meio ambiente, visto sob quatro dimensōes fundamentais: a) o indivíduo, como ser biológico, com um potencial genético e seus aspectos físicos e mentais para a saúde; b) o meio ambiente em que esse indivíduo vive, considerado na sua dimensão ecológica e social, que se localiza fora do corpo humano e sobre os quais o indivíduo tem pouco ou nenhum controle (qualidade do ar, saneamento básico, alimentação, transporte, trabalho, etc.); c) estilo de vida, seu modo especial de interagir com o meio ambiente, se compõe do conjunto de decisões individuais que afetam a saúde e sobre as quais o indivíduo pode exercer um certo grau de controle (hábitos higiênicos, sono/repouso, lazer, etc.) e, d) organização da atenção à saúde, ou seja, o grau de suporte que o indivíduo recebe de um serviço de atenção à saúde.

\section{Metodologia}

A nossa população constitui-se de pacientes cirúrgicos atendidos no Hospital das Clínicas da Faculdade de Medicina de Ribeirão Preto da Universidade de Sáo Paulo - HCFMRP-USP. Hospital escola, destinado ao ensino e à pesquisa, compartilhado por estudantes e profissionais de enfermagem, farmácia, nutrição, medicina, psicologia e outras áreas ligadas ao setor saúde.

Nossa amostra constou de pacientes cirúrgicos, atendidos no 10 semestre de 1989, adultos, residentes em Ribeirão Preto, que foram submetidos à cirúrgia eletiva de médio porte e orientados auto e halopsiquicamente. $O$ grupo constituiu-se de 50 pacientes, sendo 42 do sexo feminino e 08 (oito) do sexo masculino. A coleta de dados se deu em 05 (cinco) fases: $1^{\text {a }}$ ) consulta diária à escala de cirurgia; $2^{a}$ ) consulta ao prontuário do paciente selecionado na escala de cirurgia; 3a) visita ao paciente na unidade de internação; $4^{a}$ ) confirmação da alta e programação da visita domiciliária e 5a) visita domiciliária, entre o 50 e o 10 dia após a alta hospitalar.

As visitas domiciliárias constaram de dois momentos: o primeiro onde se dava uma entrevista semi-estruturada, com o paciente e familiares e o segundo que constava de exame físico do paciente em pós-operatório.

Para a realização da entrevista semi-estruturada, utilizamos um roteiro (anexo), que foi adaptado de instrumento elaborado pela Organização Mundial de Saúde-OMS, para o desenvolvimento de trabalho(22), abordando as necessidades de cuidados de enfermagem de pacientes cirúrgicos internados em instituições de saúde.

O referido roteiro divide-se em três partes: a primeira aborda os aspectos social/ambiental como a educação, habitação, trabalho e família, a segunda aborda as relações da pessoa com o serviço de saúde como, forma de acesso, admissão, dificuldades após a alta e qualidade de atendimento e a terceira parte, refere-se mais especificamente aos aspectos biológicos da saúde do indivíduo, levantando alteraçōes ocorridas mediante a intervenção cirúrgica.

Desta forma, foram levantados os dados necessários a nossa análise. A seguir passamos aos resultados e discussão. 
Os resultados encontrados e a sua análise, estão apresentados de forma descritiva e levando-se em conta o nosso referencial teorico, extrapolam as questões estritamente do setor saúde e avançam no sentido de apontar caminhos na área social, económica e cultural.

A partir dos dados obtidos pudemos traçar um perfil geral do grupo estudado. Um grupo predominantemente do sexo feminino, 84,0\%, com $60,0 \%$ das pessoas na faixa etária de 30 a 50 anos; com escolaridade de $1 \%$ grau incompleto $68,0 \%$; casados ou amasiados, $78,0 \%$; religiâo católica, $68,0 \%$; desempenhando atividades de trabalho de mão de obra não qualificada $72,0 \%$ e morando na periferia da cidade em casas parcialmente ou totalmente inadequadas, $80,0 \%$.

Observamos, que apesar de existirem serviços de atenção primária próximo à residência das pessoas que participaram do estudo, a maioria, $64,0 \%$, dirigiu-se diretamente ao serviço de atenção terciária. Esta inversão no fluxograma proposto para a assistência à saúde foi justificada pelos pacientes com os seguintes argumentos: desconhecer a dinâmica de atendimento do setor, ter tido experiências negativas anteriores com relação ao atendimento da rede de atenção primária, já possuir registro no serviço em que foi atendido (HCFMRP-USP) e ser parente ou amigo de pessoas que trabalham no referido serviço e que portanto facilitaram o seu atendimento.

A nosso ver, este dado reflete a desinformação da população quanto ao funcionamento dos serviços de saúde, o baixo grau de resolubilidade e de organização que caracteriza o sistema de saúde em processo de transição e também a resistência a mudanças e à assimilação de novas diretrizes de atendimento.

Observamos no grupo estudado, que apesar da maioria, $56,0 \%$ (figura 1 ) ter tido uma média de hospitalização, dentro do esperado para cirurgias eletivas de médio porte, de 3-6 dias, uma porcentagem expressiva $(30,0 \%)$, teve mais que dez (10) dias de internação. Esta ampliação do tempo de permanência, diminui a rotatividade dos leitos cirúrgicos e portanto aumenta a demanda reprimida, ou seja, aumenta o $\mathrm{n}$ de pessoas que aguardam pelo tratamento cirúrgico. $O$ adiamento da alta hospitalar deveu-se em parte pelas complicações pós-operatórias, outras vezes conseqüências das condições gerais precárias das pessoas que procuram o serviço ou mesmo decorrentes da qualidade de assistência prestada.

Abordando mais especificamente as questões ligadas à intervenção cirúrgica e à hospitalização, consideramos segundo FEIX(10), como um período de crise para o indivíduo pois altera seus ajustamentos normais nos vários setores da vida. Torna o indivíduo dependente da equipe de saúde e diminui sua capacidade de autodeterminaçāo (estilo de vida). É um processo agudo que debilita a pessoa num imediato.

Dentro do processo cirúrgico, o pós-operário é o período em que ocorre o restabelecimento do indivíduo submetido a este tratamento. Parte do restabelecimento se dá ainda no hospital e se complementa em casa após a alta. No hospital, existe todo um aparato de recursos humanos e materiais para detectar precocemente sinais e sintomas na prevenção de possíveis complicações, entretanto, no domićlio, os pacientes já não dispõem desses recursos para assistí-los. 


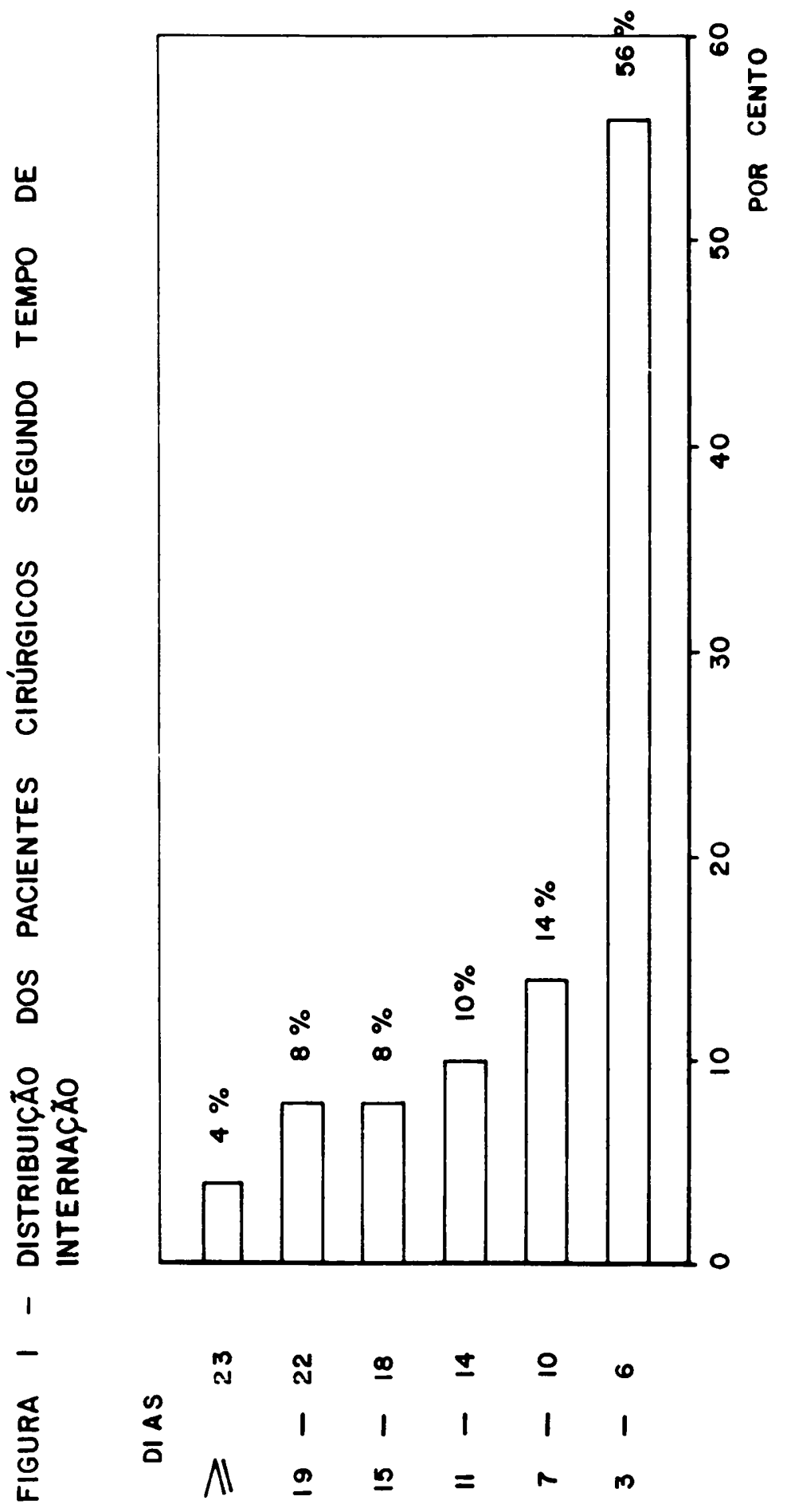


FIGURA 2 - DISTRIBUIÇÃO DAS ALTERAÇOES FUnCIONAIS DE SAUDE APRESENTADAS PELOS PACIENTES CIRURGICOS APOS ALTA HOSPITALAR

VISĀo

AUDICAOO

CABELOS /UNHAS

COMUNICACAO

CIRCULAGAO

RESPIRAÇAO

INGESTÃo / DIGESTÃo

PELE

SONO / REPOUSO

ELIMINAÇÄO

SEXUALIDADE

EMOCIONAL

SENSIBILIDADE / REGULAÇÃO

MOVIMENTAGÃo / DEAMBULAGÃo
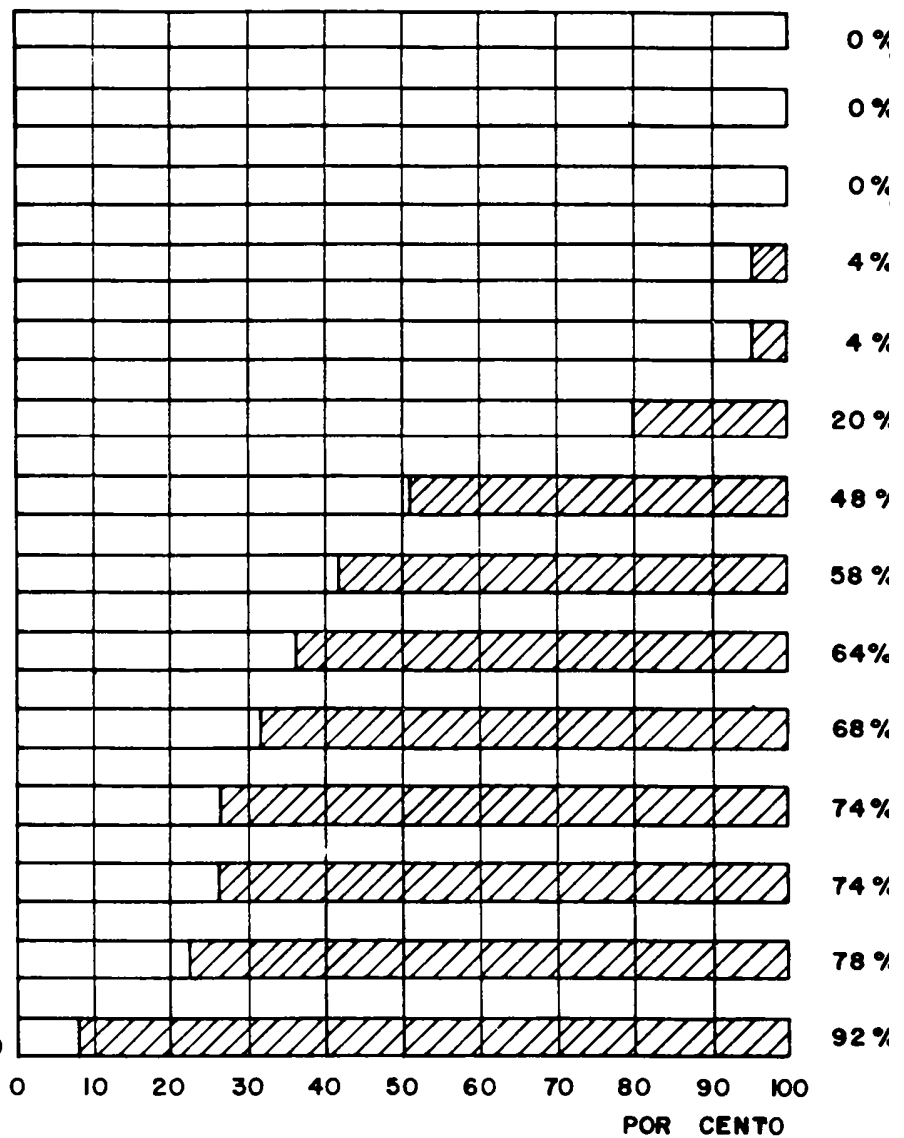

\section{QZय FUNGÃo ALTERADA}

$\square$ FUnCAO MAMTIDA 
O retorno da pessoa para o seu domícilio, ocasiona a reestruturação da organização familiar, pois, é a família que passa a assumir a funçāo assistencial, neste sentido, são muitas as dúvidas apresentadas por elas, sobre a forma pela qual lidar com as alterações decorrentes da cirurgia e mesmo que sinais e sintomas são esperados e quais são indicativos de complicaçôes.

$\mathrm{Na}$ figura 2, podemos observar o tipo e a incidência das alterações apresentadas pelo grupo estudado.

A restrição à movimentação foi a alteração mais referida pelos pacientes $(92,0 \%)$ e deveu-se principalmente à desinformação à respeito de quando e como poderiam retornar às atividades, assim como ao receio da dor e da abertura da ferida cirúrgica.

As alterações de sensibilidade e regulação, que dizem respeito à dor e hipertermia, sintomas comuns no pós-operatório, foram referidos por $78,0 \%$ dos pacientes e tiveram como solução em grande parte dos casos a auto-medicação.

Em relação às manifestações emocionais, referidas por $74 \%$ das pessoas e segundo SOARES(21), uma reação comumente apresentada pelo paciente cirúrgico, teve como causas manifestadas; a incerteza quanto à evolução e prognóstico do tratamento, complicações pós-operatórias, situação irregular no trabalho e situação económica instável. As alterações de sexualidade, foram referidas por $74,0 \%$ do grupo. Há que se lembrar, que ogrupo se constituiu em sua maioria por adultos jovens, que se supōe em fase sexualmente ativa e preocupados em retornar às atividades normais também neste aspecto.

Problemas de eliminação, foram apresentados por $68,0 \%$ das pessoas e o mais comum foi a constipação intestinal, que determinou a auto-medicação ou a utilização de dietas laxativas para solucioná-la. Em trabalho(11) realizado a respeito das alteraçóes de hábito intestinal de pacientes internados, observou-se que $67,0 \%$ das pessoas apresentaram constipação intestinal. No paciente cirúrgico, esta alteração está associada à mudança de dieta, à permanêncía no leito por longo perfodo ao estresse e ao tipo de cirurgia(2).

As dificuldades apontadas para o sono e repouso, tiveram freqüência de $64,0 \%$ e foram identificadas como causas básicas a dor, a restrição à movimentação e o emocional. A solução mais freqüentemente dada, também foi a auto-medicação. Os hematomas nos membros superiores, decorrentes de soroterapia, o edema e a dor no local cirúrgico, queimaduras por causas inespecíficas e a deiscência de sutura, foram as alterações de pele apresentadas por $56,0 \%$ do grupo. '

Estas foram as alterações mais frequentes no pós-operatório dos pacientes em estudo e foram fontes geradoras de problemas tanto para o paciente como para a família que não se sentiram devidamente preparados para enfrentá-los, quando no domićlio.

Passando à análise das percepçóes dos pacientes frente à experiência cirúrgica temos que, em resposta à questão: que dificuldades encontrou após a alta hospitalar? As pessoas se colocaram e puderam mostrar como estavam vivenciando o fato de terem sido operadas e estarem retornando para suas casas (figura 3 ).

As dificuldades relacionadas à mudança do estilo de vida, referidos pela maior parte das pessoas, refletiram o desconforto da diminuição do poder de decisão individual frente às limitações decorrentes do processo cirúrgico, levaram a limitação na auto-determinação, modificando hábitos e relaçōes e ficaram muito evidentes no pós-operatório no domićlio. 


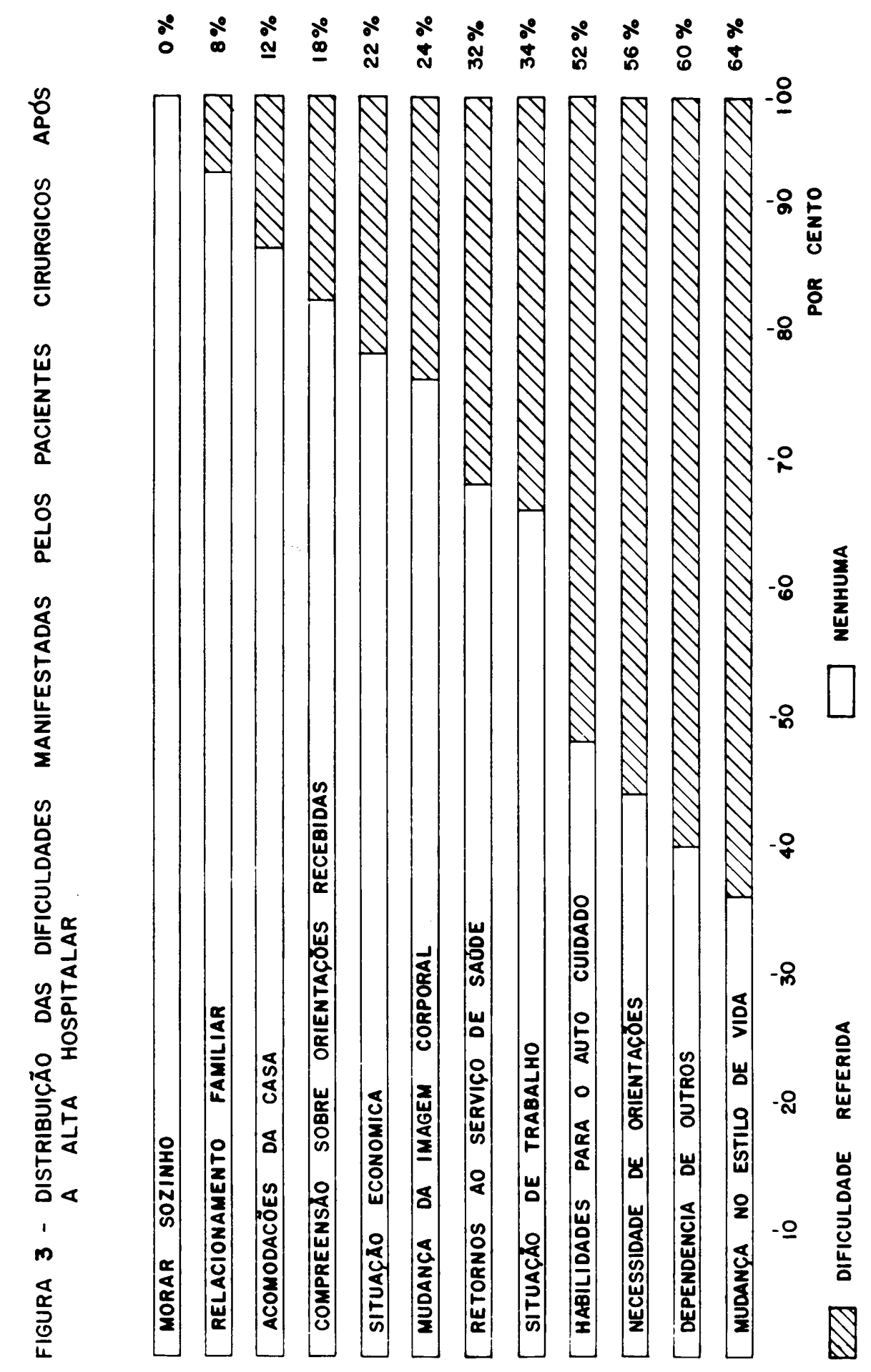


Estas mudanças se evidenciaram tanto no relacionamento social e familiar como nas acomodações da casa que se viram alteradas para atender da melhor forma à pessoa no seu restabelecimento, assim não só os familiares se reorganizaram como tambem o ambiente.

Na mesma linha das alterações do estilo de vida, estão as referências à dependência de outros, da equipe de saúde e dos familiares. Nenhuma pessoa que retorna do hospital, estará totalmente independente, algumas retornam com relativa independéncia enquanto outras podem nunca mais serem independentes. Em ambas situações, as pessoas necessitam compreender e aceitar as mudanças provisorias ou definitivas em suas vidas(9).

As dificuldades apontadas para o auto-cuidado, estão relacionadas à necessidade de orientação de maneira geral e foram expressadas pelo grupo com perguntas como: o que estou sentindo é normal? aonde me dirigir em caso de urgência? ou, quando poderei voltar às minhas atividades e ao trabalho?

O conhecimento dos sinais e sintomas comuns no pós-operatório, das possíveis complicações; das orientações sobre o auto-cuidado e da prevençâo de futuras complicaçóes, devem fazer parte de um plano para a alta. Segundo CLAUSEN(6), o planejamento para a alta encoraja o paciente e a família a enfrentar os problemas oriundos da cirurgia e promove o crescimento para a independência, dentro das condições possíveis.

Passando às dificuldades apontadas em relação às atividades de trabalho, elas são praticamente o reflexo da situação precária em que se desenvolvem estas atividades (tabela 1).

Em relação aos retornos, a maior parte dos pacientes foi atendida no próprio serviço onde trancorreu a cirurgia (HCFMRP-USP) e não nos serviços da rede básica de saúde próximos às suas residéncias, o que foi referido como problema pelos pacientes em relação a distância e ao transporte, extremamente precário para uma situação de pós-operatório. Ainda quanto à dificuldade de retorno foi colocado o problema das filas e da demora no atendimento.

No que se refere à percepção dos pacientes quanto a qualidade de atendimento, 78,0\% considerou ter sido positiva, o que a nosso ver, não reflete os problemas enfrentados por eles, desde o acesso ao serviço, o tempo de espera, as complicações, as dificuldades de retorno, a desinformação e a ansiedade. Isto nos leva a crer que estas pessoas desconhecem seu direito à saúde e dessa forma não esperam e nem reivindicam por melhor qualidade de assistência, principalmente se levarmos em consideração a quantidade de recursos para a saúde, existentes hoje no município de Ribeirão Preto, que estão além dos preconizados pela OMS. Existe um (01) trabalhador de saúde para cada 65 habitantes e 6,3 leitos hospitalares para cada 1000 habitantes, quando o preconizado é de 3 a 5 leitos/1000 habitantes(15). Desta forma, a partir dos dados levantados, pudemos chegar a algumas conclusões: 
TABELA 1. Distribuição das atividades de trabalho dos pacientes cirúrgicos e formas de afastamento

\begin{tabular}{|c|c|c|c|c|c|c|}
\hline \multirow[b]{2}{*}{$\begin{array}{l}\text { ATIVIDADE DE } \\
\text { TRABALHO }\end{array}$} & \multicolumn{2}{|c|}{ REMUNERADO } & \multicolumn{2}{|c|}{ NÄO REMUNERADO } & \multicolumn{2}{|c|}{ TOTAL } \\
\hline & N2 & $\%$ & N2 & $\%$ & N2 & $\%$ \\
\hline Do Lar & - & - & 16 & 32,0 & 16 & 32,0 \\
\hline Pequeno Comerciante & - & - & 6 & 12,0 & 6 & 12,0 \\
\hline Servente & 4 & 8,0 & 1 & 2,0 & 5 & 10,0 \\
\hline Doméstica & - & - & 4 & 8,0 & 4 & 8,0 \\
\hline Escriturária & 2 & 4,0 & - & - & 2 & 4,0 \\
\hline Auxiliar de Enfermagem & 1 & 2,0 & - & - & 1 & 2,0 \\
\hline Bancário & 1 & 2,0 & - & - & 1 & 2,0 \\
\hline Oficial de Justiça & 1 & 2,0 & - & - & 1 & 2,0 \\
\hline Cozinheira & 1 & 2,0 & - & - & 1 & 2,0 \\
\hline Artesăo & - & - & 1 & 2,0 & 1 & 2,0 \\
\hline Manicure & - & - & 1 & 2,0 & 1 & 2,0 \\
\hline Costureira & - & - & 1 & 2,0 & 1 & 2,0 \\
\hline Operário & - & - & 1 & 2,0 & 1 & 2,0 \\
\hline Aposentado & 8 & 16,0 & - & - & 8 & 16,0 \\
\hline Desempregado & - & - & 1 & 2,0 & 1 & 2,0 \\
\hline TOTAL & 18 & 36,0 & 32 & 64,0 & 50 & 100,0 \\
\hline
\end{tabular}

\section{Conclusões e Considerações Finais}

Apesar do presente trabalho ter sido realizado com uma amostra de pacientes do HCFMRP-USP, consideramos que muitas das suas conclusões possam ser extensivas à outros pacientes que passem por experiência semelhante.

Neste estudo, pudemos observar que; o grupo caracterizou-se em sua maioria, pelo baixo nível instrucional, pelas condições precárias de moradia, transporte e instabilidade no trabalho.

Precisando de assistência à saúde, a maioria das pessoas do grupo dirigiu-se diretamente ao serviço de atenção terciária, invertendo-se assim o fluxograma proposto pela atual política de saúde, que prevê a entrada do indivíduo no sistema pelos serviços de atenção primária.

Observamos também que quando de alta, estes pacientes não são encaminhados ao serviço da rede básica de saúde mais próximo à sua residência, para continuidade do tratamento, configurando-se assim a desarticulação ainda existente entre atendimento hospitalar e extra-hospitalar. 
Dessa forma, ao sair de alta, o paciente e a familia assumem a responsabilidade do cuidado pós-operatório, evidenciando-se então o seu despreparo para assumirem o cuidado. Os problemas enfrentados pelo paciente e família, nem sempre tiveram uma solução adequada, deixando clara a necessidade de um acompanhamento, pós-operatório destes pacientes, por profissionais de enfermagem.

Diante destas conclusões, consideramos oportuno fazer algumas sugestões, tanto à nível administrativo, como à nível de assistência de enfermagem. São propostas alternativas para a assistência hospitalar e para o incentivo d̀s estruturas extra hospitalares de apoio à saúde.

\section{Sugestões}

01. Implantação, nas unidades de internação cirúrgica, de sistemática de assistência de enfermagem, que permita o levantamento de problemas potenciais dos pacientes, que avalie a sua prontidão para o auto cuidado e para a alta.

02. Tendo em vista que a alta é uma transferência da responsabilidade do cuidado, para o paciente e sua família, necessário se faz a implantação de programas sistematizados de orientação para alta, individualizados. Programas estes, que contemplem os aspectos gerais, a serem abordados com todos os pacientes e que culminem com aspectos específicos da cirugia a que o paciente foi submetido.

03. Tendo em vista a quantidade de informações para a alta e a dificuldade de memorização por parte do paciente e da família, devido à ansiedade apresentada nesta situação, consideramos oportuna a elaboração de folhetos informativos simplificados, a serem entregues no momento da alta. Este folhetos devem conter orientações gerais e específicas a respeito do pós-operatório, assim como informações a respeito do retorno e as formas de acesso ao serviço de saúde quando necessário.

04. Atendendo às diretrizes propostas para o setor saúde, fazer o encaminhamento do paciente de alta, para os serviços da rede básica com vistas à continuidade do atendimento. $O$ paciente deverá ser encaminhado levando consigo um resumo do atendimento efetuado na área hospitalar e as indicaçōes para os cuidados a serem prestados.

05. Considerando-se a necessidade de articulação entre os hospitais e a rede básica de saúde, é importante que as unidades de internação possuam um guia de informações com o mapa de localização dos postos de atendimento, assim como a relação das modalidades de atendimento que os mesmos realizam. Este instrumento facilitará o encaminhamento dos pacientes.

06. Tendo em vista esta dinâmica, consideramos imprescindível uma avaliação do aparelhamento material e dos recursos humanos da rede básica de saúde, 
afim de viabilizar o atendimento dos pacientes referenciados pelos hospitais.

07. Estabelecer um esquema de visita domiciliária para pacientes cirúrgicos pós alta, afim de que se possa realizar a avaliação de qualidade do serviço prestado e detectar problemas que não.foram resolvidos e que necessitam de reorientação.

08. Que seja estimulada a formação de grupos de pacientes, com sequelas funcionais permanentes decorrentes de intervenção cirúrgica, a exemplo do grupo de colostomizados e de mastectomizadas em funcionamento na Escola de Enfermagem R. P. USP contando com a participaçăo de enfermeiros do Hospital das Clínicas.

09. Que as consultas e retornos ambulatoriais sejam efetuados com hora marcada, afim de que o paciente não passe pelo desconforto de permanecer várias horas à espera do seu atendimento.

10. Que a enfermagem faça uma triagem dos pacientes que chegam para consulta ou retorno, afim de dar prioridade de atendimento para aqueles que se encontram em situação mais crítica.

11. Que a "sala de espera", para a consulta ou atendimento, seja utilizada como oportunidade de educação para saúde.

12. Que, no sistema telefónico, seja implantado um ramal "disque dúvidas", para pacientes que saindo de alta, apresentem necessidade de alguma orientação.

13. Que se estude a possibilidade de criação de uma unidade de cuidados intermediários de enfermagem, para pacientes com alta mas, que ainda năo estejam preparados para deixarem o hospital. Este serviço se torna muito útil, principalmente para aquelas pessoas que apresentam sequelas funcionais ou que necessitam desenvolver habilidades especificas de auto cuidado.

14. Que no processo de formação dos profissionais da área de saúde, seja dado enfoque não só às questões biológicas da assistência mas uma visão do homem como um todo, inserido num dado contexto sócio-económico e cultural.

Nossas conclusões não pretendem ser definitivas e acreditamos que futuros trabalhos possam vir corroborar as idéias aqui contidas. Esperamos, entretanto, podermos com o presente estudo, contribuir para o dimensionamento da atuação de enfermagem tanto a nível hospitalar como extra-hospitalar, busca-da melhoria da qualidade de assistencia prestada à população. 
AGUILLAR, O. M.; ANGERAMI, E. L. S. The discharge of a surgical patient in the context of the health sistem. Rev. Esc. Enf. USP., v. 26, n. 3, p. - , dec., 1992.

Based on the assumption that surgical patients, together with their families, take responsibility for otheir own care after being discharged from the hospital and thet they are not duly prepared for this task, we indertook the present study to investigate the problems of surgical patients related to discharge and to determine the type of care offered to these individuals within the context of the health system.

The study inclued patients submitted to elective, medium surgery at the University Hospital, Faculty of Medicine of Ribeirão Preto, USP, during the first semester of 1989. Fifty patients (42 women and 8 men) of the various surgical specialties were interviewed during home visits. The instrument for data collection consisted of three parts: the first involved social and enviromental aspects such as housing, job, family and others, the second involved the relationship of the individual with the health system, his/her perceptions and difficulties, and the third involved the biological aspects related to the surgical process. The data were analyzed in a descriptive manner on the basis of the theoretical referencial of Lalonde, which sees health as the result of a dynamic process of individual integration with the environment.

Outpatient.

UNITERMS: Surgical Patients. Discharge from Hospital Assessment of Postoperative

\section{REFERÊNCIAS BIBLIOGRÁFICAS}

1. BRASIL. Ministério da Previdência e Assistência Social. Instituto Nacional de Assistência Médica da Previdência Social. O INAMPS na Nova República. Brasília, s. d.

2. BRUNNER, L. S.; SUDDART, D.S. Enfermagem médico-cinúngica. 3. ed. Rio de Janeiro, Interamericana, 1977 .

3. BUCK, C. Después de Lalonde: hacia la generactión de salud. Bol. Epidemol, v. 6, n² 1, p. 10-5, 1986.

4. CALDERA, K. Exploration of the effect of educational level on the nurse's attitude toward discharge teaching. J.Nurs.Educ., v. 19, n०8, p. 24-32, 1980.

5. CHAVES, M. M. Regionalização docente-assistencial e niveis de assistência. /Apresentado ao Seminário sobre Hospitais de ensino, Rio de Janeiro, $1975 /$.

6. CLAUSEN, C. Staff. RN: a discharge planner for every patient. Nurs.Manage, v. 15, $n^{\circ} 11, p .58-61$, 1984.

7. CONSELHO FEDERAL DE ENFERMAGEM. O Exercício da enfermagem nas instituiçöes de Saúde do Brasil 1982/1983: força de trabalho em enfermagem. Rio de Janeiro, ABEn, 1985. v. 1.

8. DREW, L. A.; BIORDI, D; GILLIES, D. A how discharge planners and home health nurses view. their patientes. Nurs. Manage, v. 19, $\mathrm{n}^{9} 4$, p. 66-70, 1988.

9. FAULKNER, A. Nursing: a criative approach. London, Bailliere - Tindall, 1985.

10. FEIX, M. A. F. O paciente hospitalizado e a incisão cinúngica abdominal: problemas, percepçōes e expectativas. São Paulo, 1984. 84p. Dissertaçāo (Mestrado) - Escola de Enfermagem, Universidade de São Paulo.

11. HARDER, L. M. Alteraçöes dos hábitos de eliminação intestinal em pacientes hospitalizados. São Paulo, 1982, 83p. Dissertação (Mestrado) - Escola de Enfermagem, Universidade de São Paulo.

12. KISIL, M. Niveis de atenção num hospital-escola: avaliação através da complexidade tecnologica dos métodos diagnósticos. São Paulo, 1977. Dissertação (Mestrado) - Faculdade de Medicina, Universidade de São Paulo. 
13. LONG, B. C.; GOWIN, C. Y.; BUSHONG, M. E. Surgical intervention. In: PHIPPS, W. J. et al. Medical-surgical nursing-concepts and clinical practice. 2. ed. London, Mosby, 1983. p. 401-62.

14. MAHLER, H. El sentido de "la salud para todos en el ano $2000^{\prime \prime}$. Foro Mund Salud, v. 2, n 1, p. 5-25, 1981.

15. MISHIMA, S. M. Recursos humanos em saúde na implantação das açōes integradas de saúde no munictpio de Ribeirão Preto. Ribeirāo Preto, 1988. /Mimeografado/

16. MISHIMA, S. M.; SILVA, E. M.; ALMEIDA, M. C. P. Recursos médico-sanitários do munićpio de Ribeirão Preto. Rev. Med, v. 21, no 1/2, p. 23-42, 1988.

17. ORGANIZAÇĀO MUNDIAL DA SAÚDE. Cuidados primánios de saúde: relatório da Conferencia Internacional sobre cuidados primários de saúde, Alma-Ata, URSS, 1978. Brasília, UNICEF, 1979.

18. ORGANIZAÇÃO PANAMERICANA DE LA SALUD. El concepto del "campo de salud": una perspectiva canadiense Bol. Epidemol., v. 4, n. 5, p. 13-5, 1983.

19. PEARLMAN, I. R. Discharge planning: the team is behing you! Nurs. Manage, v. 15, no 8, p. 36-8, 1984.

20. RIBEIRÃO PRETO (cidade). Secretaria Municipal de Saúde. Plano de Saúde para Ribeirão Preto, 1989. Ribeirão Preto, 1989./Mimeografado/

21. SOARES, J. Extensão da cobertura por serviços básicos de saúde: participaçăo do Ministério da Previdencia e Assistencia Social. IN: CONFERÊNCIA NACIONAL DE SAÚDE, 7., Braślia, 1980. Anais. Brasflia, Centro de Documentação do Ministério da Saúde, 1980. p. 69-73.

22. WORLD HEALTH ORGANIZATION. REGIONAL OFFICE FOR EUROPE. Final report on the workshop on the nursing process. Copenhagen, 1982. AMimeografado/

\section{ANEXO}

INSTRUMENTO PARA COLETA DE DADOS DO PACIENTE CIRÚRGICO

NOME:

RG:

ENDEREÇO:

DATA DA VISITA:

\section{DADOS SOCIAL/AMBIENTAL}

1. Idade:

2. Estado civil:

3. Sexo: Masc. ( )

Fem. ( )

4. Religião:

5. Escolaridade:

10 grau incompleto ( )

19 grau completo ( )

$2 \%$ grau incompleto ( )

$2 \%$ grau completo ( )
39 grau incompleto ( )

3\% grau completo ( )

nenhuma 
6. A comunicação é facilmente estabelecida entre a enfermeira e a pessoa:

Sim ( )
Não( )

7. Pessoas que participaram da entrevista no domićlio:

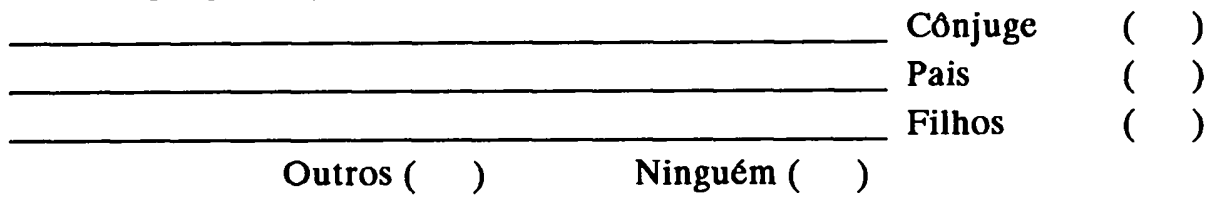

8. Caracterização da residência enquanto acomodação apropriada ao bem estar e saúde:

$$
\begin{aligned}
& \text { Adequada } \\
& \text { Parcialmente adequada } \\
& \text { Inadequada }
\end{aligned}
$$

9. A intervenção cirúrgica determinou mudanças nas atividades:

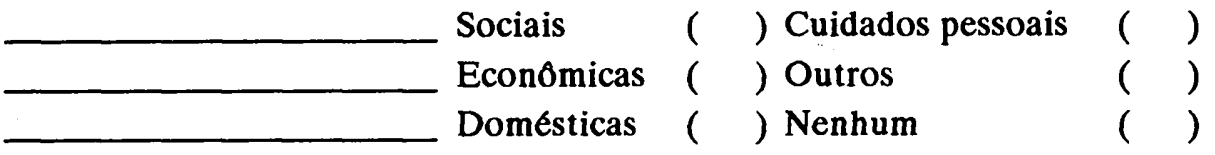

10. Conta com a ajuda de alguém no pós-operatório:

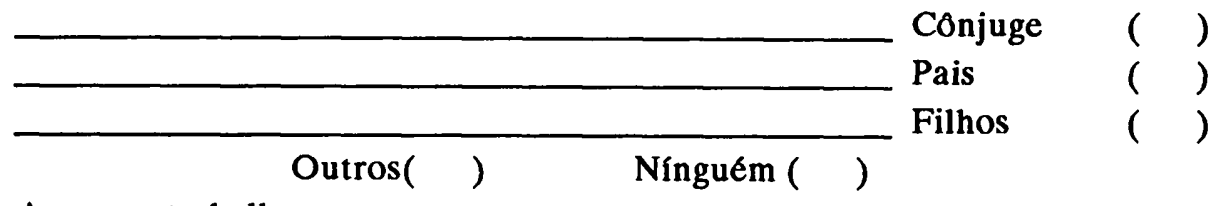

11. A pessoa trabalha:

$$
\begin{aligned}
& \text { Não } \\
& \text { Sim } \\
& \text { Afastado com remuneração } \\
& \text { Afastado sem remuneração } \\
& \text { Outros }
\end{aligned}
$$

\section{HISTÓRIA DE SAÚDE}

1. Dados da internação:

Data da admissão:

Data da alta:

Data da cirurgia:

2. Forma de admissão:

$$
\begin{aligned}
& \text { Urgência } \\
& \text { Não urgência }
\end{aligned}
$$


3. Como se deu o acesso ao serviço:

4. Razões pela qual a pessoa procurou o serviço de saúde:

Encaminhado pela rede básica de saúde Direto ao Hospital das Clínicas Outros Diagnóstico ( ) Reabilitação Tratamento ) Outros

5. Diagnóstico cirúrgico: Ações preventivas

6. Percepção da pessoa frente à experiência com o serviço de saúde:

$\begin{array}{ll}\text { Positiva } & (\text { ) Negativa } \\ \text { Aceitável } & (\text { ) Outros }\end{array}$

7. Dificuldades encontradas após a alta hospitalar:

Habilidade para o autocuidado Acomodações da casa Morar sozinho

Depender dos outros Relacionamento familiar Situação de trabalho Situação financeira Mudança no estilo de vida Mudança na imagem corporal Compreensão sobre orientações Retornos ao serviço de saúde Necessidade de orientações

8. Faz uso de medicação em decorrência da cirurgia realizada:

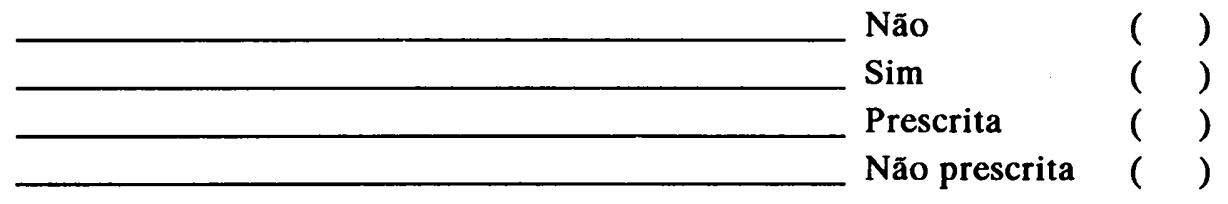


FUNÇĀO

PROBLEMA

SOLUÇÃO

1. Respiração

Padrão usual:

Mantido

Alterado

2. Circulação

Padrão usual:

Mantido

Alterado

3. Ingestăo/Digestão

Padrăo usual:

Mantido

Alterado

4. Eliminação

Padrão usual:

Mantido

Alterado

5. Pele

Padrão usual:

Mantido

Alterado

6. Cabelos/Unhas

Padrão usual:

Mantido

Alterado
1.1. Respiração

2.1. Circulação

3.1. Ingestão/Digestão

$$
\text { ( ) }
$$

4.1. Eliminação

5.1. Pele

6.1. Cabelos/Unhas
1.2. Respiração

Nutricional

Farmacologica

Técnica

Outros

2.2. Circulação

Nutricional

Farmacologica

Técnica

Outros

3.2. Ingestăo/Digestão

Nutricional

Farmacologica

Técnica

Outros

4.2. Eliminação

Nutricional

Farmacológica

Técnica

Outros

5.2. Pele

Nutricional

Farmacológica

Técnica

Outros

6.2. Cabelos/Unhas

Nutricional

Farmacologica

Técnica

Outros 
7. Sensibilidade/

Regulação

Padrão usual:

Mantido

Alterado

8. Visão

Padrão usual:

Mantido

Alterado

9. Audição

Padrăo usual:

Mantido

Alterado

10. Sono/Repuso

Padrão usual:

Mantido

Alterado

11. Movimentação/

Deambulação

Padrão usual:

Mantido

Alterado

12. Comunicação

Padrão usual:

Mantido

Alterado

13. Sexualidade

Padrão usual:

Mantido

Alterado
7.1. Sensibilidade/

Regulaçăo

( )

8.1. Visão

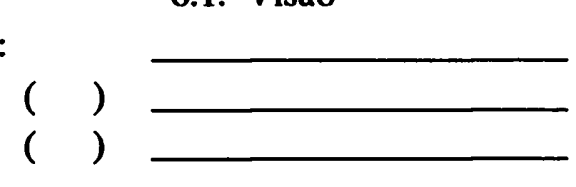

9.1. Audição

10.1. Sono/Repouso

11.1. Movimentação/

Deambulação

$$
\text { ( ) }
$$

12.1. Comunicação

13.1. Sexualidade
7.2. Sensibilidade/

Regulaçăo

Nutricional

Farmacologica

Técnica

Outros

8.2. Visão

Nutricional

Farmacologica

Técnica

Outros

\subsection{Audição}

Nutricional

Farmacológica ( )

Técnica

Outros

10.2. Sono/Repouso

Nutricional

Farmacologica

Técnica

Outros

11.2. Movimentação/

Deambulação

Nutricional

Farmacológica

Técnica

Outros

12.2. Comunicação

Nutricional

Farmacologica

Técnica

Outros

13.2. Sexualidade

Nutricional

Farmacológica

Técnica

Outros 
14. Emocional

Padrão usual:

Mantido

Alterado
14.1. Emocional

(

()

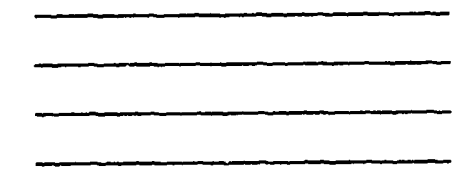

14.2. Emocional

Nutricional

Farmacologica

Técnica

Outros
( )

( )

( )

( ) 